\title{
Corrigendum: BMP4-Induced Differentiation of Human Hair Follicle Neural Crest Stem Cells into Precursor Melanocytes from Hair Follicle Bulge
}

Jung-Ho Yoon, Ho-Jin Kim, Jung-Hwan Kim, Tae-Hoon Kim, Chang-Hoon Seo ${ }^{1}$, Young Kwan Sung ${ }^{1}$, Ki-Ho Kim

Department of Dermatology, College of Medicine, Dong-A University, Busan, ${ }^{1}$ Department of Immunology, School of Medicine, Kyungpook National University, Daegu, Korea

We found that the co-author's name in article above was published incorrectly. The name 'Yeong-Kwan Sung' should be 'Young Kwan Sung'.

Before correction:

Jung-Ho Yoon, Ho-Jin Kim, Jung-Hwan Kim, Tae-Hoon Kim, Chang-Hoon Seo ${ }^{1}$, Yeong-Kwan Sung ${ }^{1}$, Ki-Ho Kim

After correction:

Jung-Ho Yoon, Ho-Jin Kim, Jung-Hwan Kim, Tae-Hoon Kim, Chang-Hoon Seo ${ }^{1}$, Young Kwan Sung ${ }^{1}$, $\mathrm{Ki}-\mathrm{Ho} \mathrm{Kim}$

We sincerely apologize for any confusions that we may have caused.

This is an Open Access article distributed under the terms of the Creative Commons Attribution Non-Commercial License (http://creativecommons.org/ licenses/by-nc/4.0) which permits unrestricted non-commercial use, distribution, and reproduction in any medium, provided the original work is properly cited.

Copyright $\odot$ The Korean Dermatological Association and The Korean Society for Investigative Dermatology 